Original Research Paper

\title{
Homogenization of Earthquake Catalogue in Terms of Magnitude in Iran and Adjoining Region
}

\author{
${ }^{1}$ Noushin Naraghiaraghi, ${ }^{1}$ Mohd Nawawi, \\ ${ }^{1}$ Syed Mustafizur Rahman, ${ }^{2}$ Ali Beitollahi, ${ }^{1}$ Rosli Saad and ${ }^{3}$ Samieh Joneidi \\ ${ }^{1}$ School of Physics, University Science Malaysia, Penang, Malaysia \\ ${ }^{2}$ Department of Earthquake, Building and Housing Research Center, Tehran, Iran \\ ${ }^{3}$ Petroiran Development Company (PEDCO), Tehran, Iran
}

\author{
Article history \\ Received: $12-10-2014$ \\ Revised: 31-03-2016 \\ Accepted: 01-04-2016 \\ Corresponding Author: \\ Noushin Naraghiaraghi \\ School of Physics, University \\ Science Malaysia, Penang, \\ Malaysia \\ Email: nooshin_na@yahoo.com
}

\begin{abstract}
In any seismic hazard assessment a uniform earthquake catalogue is an essential parameter. In this research, an earthquake catalogue of Iran and adjacent areas was studied, using national and international catalogues. The considered region covers a quadrangle limited by 23 to $42^{\circ} \mathrm{N}$ and 42 to $65^{\circ} \mathrm{E}$ including Iran and adjacent areas. Earthquake data from the third millennium BC until 2014 were considered in this study. The standardization of the catalogue in terms of magnitude was achieved and new relations were generated to convert all types of magnitude into moment magnitude by using the orthogonal regression technique. Based on the proposed relations, $M_{W}$ can be estimated and considered as a unified magnitude scale.
\end{abstract}

Keywords: Orthogonal Regression, Earthquake Catalogue, Magnitude Conversion, Iran and Adjoining Region

\section{Introduction}

The earthquake magnitude scale is an important parameter for quantification of earthquakes. Station distribution, changes in instrumentation, the magnitude formula and the data reduction method cause different magnitude scale reports therefore use of a uniform scale is not always possible (Kanamori, 1983).

As a result, different magnitude scales such as $M_{L}$, $M_{S}$ and $m_{b}$ have been developed and are currently in use. This research aims to standardize the event catalogue in terms of magnitude and generate a uniform catalogue with moment magnitude because compilation of a homogeneous earthquake catalogue is an essential tool for the seismic hazard evaluation. All available international and national catalogues were used to compile the new catalogue. To achieve this goal orthogonal regression method between different magnitude types is used. The final catalogue includes the events from the third millennium BC to 2014 .

Different magnitude scales behave variously for all magnitude ranges and for large earthquakes they show saturation effects at different levels. These limitations cause over-estimation or under-estimation of earthquake magnitudes (Scordilis, 2006). Other magnitude scale based on seismic moment, $M_{W}$, is considered as the most reliable magnitude because of having no saturation limits
(Kasahara, 1981). Moment magnitude can be calculated while moment-tensor solution is available and it has several benefits comparing with other magnitude scales.

Moment magnitude is a physical parameter of the earthquake and quantitatively links the earthquake process to tectonic deformation (Kagan 2002a; Bird and Kagan, 2004). It does not saturate for large earthquakes and the accuracy is two to three times higher than other magnitudes (Kagan, 2002b; 2003).

The main objective of this research is to develop valid empirical relations converting all kind of magnitude scales to moment magnitudes in order to make a uniform event catalogue based on moment magnitudes. Such relations are useful for compiling uniform earthquake catalogues.

\section{Materials and Methods}

Magnitude of an earthquake is the most commonly used descriptor for earthquake size. Body wave magnitude $\left(m_{b}\right)$, Surface wave magnitude $\left(M_{S}\right)$ and Local magnitude $\left(M_{L}\right)$. Local magnitudes $\left(M_{L}\right)$ are the most commonly reported magnitudes in seismic catalogues defined by Richter (1935). Body wave magnitude and the surface wave magnitude were proposed later.

Historical events as well as Instrumental data were used in this study. A comprehensive historical catalogue 
for Iran earthquakes was compiled by (Berberian, 1994 and Ambraseys and Melville, 1982).

International databases and regional sources have been consulted for the catalogue construction as followed:

- International Institute of Earthquake Engineering and Seismology (IIEES)

- Iranian Seismological Center (IRSC)

- Building and Housing Research Center (BHRC)

- ISC, International Seismological Centre UK

- NEIC, National Earthquake Information Center

- HRVD, Harvard CMT Catalogue, Harvard Centroid Moment Tensor Catalogue

- MOS, Institution of the Russian Academy of Sciences

Iran plateau is situated between the interaction of Arabian plate and Eurasian plate. Iran is situated between two old continents Eurasia; in north and Africa-Arabia in south and is known for its tectonics (Jarahi et al., 2016).

Figure 1 shows the epicenter of earthquakes in study area. The quantity and reliability of these contributions ensured that the catalogue is well defined. For most of the Iranian earthquake events after 1963 only $m_{b}$ was reported. $m_{b}$ saturates for magnitudes bigger than 6.2
(Singh et al., 1983). $M_{S}$ saturation level is around magnitude 8 , so it would be reliable for earthquakes less than magnitude 8 . The most suitable magnitude for earthquake and seismic studies is moment magnitude because of having no saturation limits (Kasahara, 1981) and moment magnitude is an input parameter for most of the predicted ground motion equations (Karimiparidari et al., 2013).

Moment magnitude is not reported for historical events and this work has extended the relationships achieved from the instrumental part. These relations are used to convert the magnitudes of historical events into moment magnitude. All catalogues together have been used to develop the equations.

For studies related to earthquake catalogues, it is important to know how different magnitude scales compared with each other (Kagan, 2003). Many empirical relationships have been developed between various magnitude scales for mapping one magnitude type into the other for different regions in the world.

Use of least square linear regression may lead to incorrect results. In such situation, it is suitable to use orthogonal regression procedure (Stromeyer et al., 2004; Joshi and Sharma, 2008; Thingbaijam et al., 2008; Ristau, 2009; Das et al., 2012).

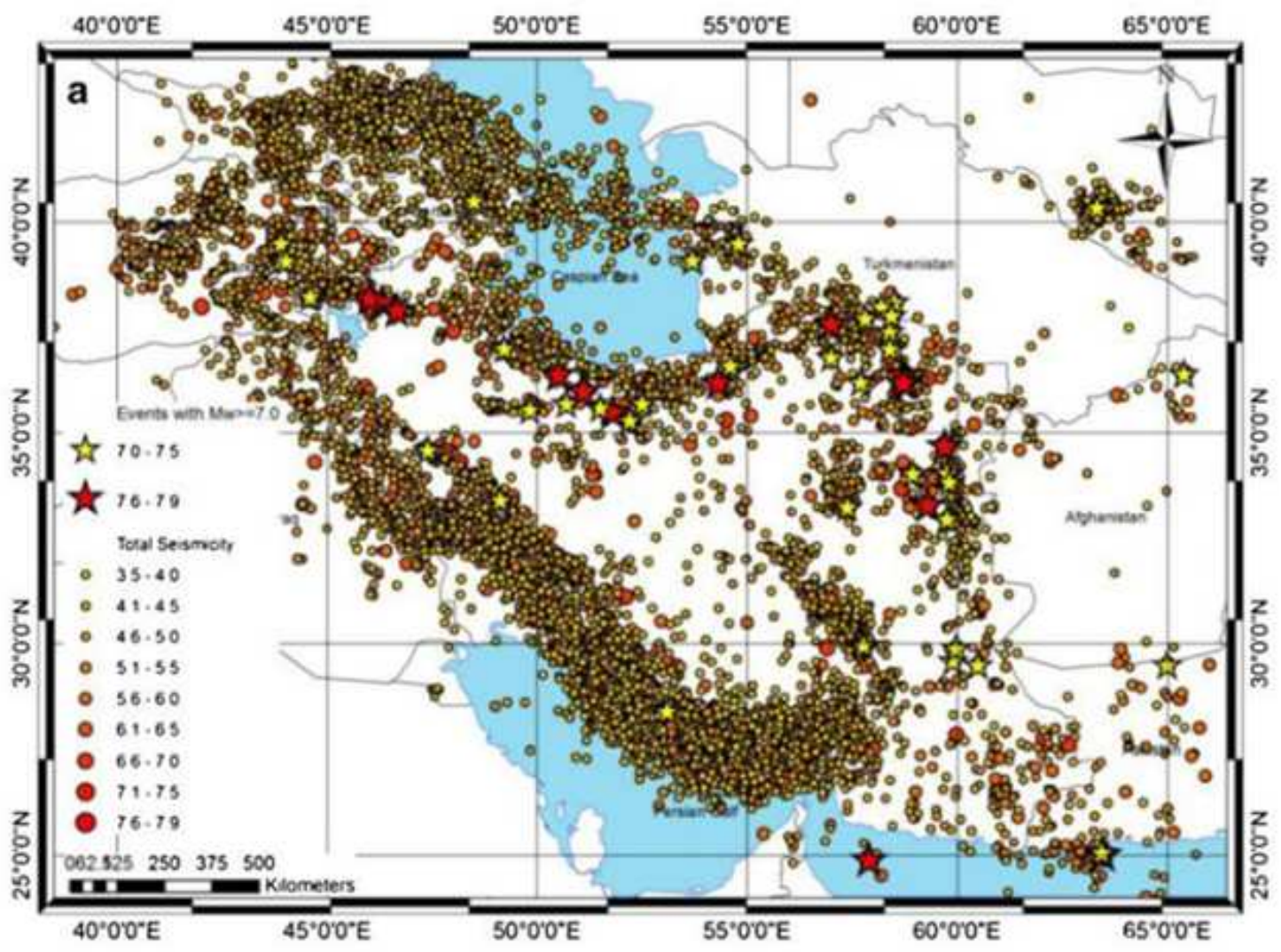

Fig. 1. Epicenters of the earthquakes in study area 
However, this regression procedure requires the knowledge of the error variance ratio for the two magnitudes, which is usually not known. An alternative to this problem is to take the error variance ratio equal to unity, assuming that error variance of different magnitudes are approximately equal (Stromeyer et al., 2004; Gutdeutsch et al., 2002; Kaverina et al.,1996; Cavallini and Rebez, 1996; Panza et al., 1993; Gusev, 1991; Ambraseys, 1990). Orthogonal standard regression is used to generate the relations. The details of the orthogonal regression procedure for estimating regression parameters are explained in the literature (Castellaro and Bormann, 2007; Carroll and Ruppert, 1996; Madansky, 1959; Kendall and Stuart, 1946).

This study reviews Orthogonal Regression (OR) (Castellaro and Bormann, 2007), General Orthogonal Regression (GOR), Inverted Standard Least Squares Regression (ISR) and Standard Least-Squares Regression (SR). The relationships were developed for $M_{S}, m_{b}$ and $M_{L}$ (local magnitude).

\section{Results}

Homogeneity of the data is considered as one of prime requirements for the catalogue. This study developed several relationships between moment magnitude and other magnitude types in order to convert them into $M_{W}$.

\section{The Conversion of Body-Wave Magnitude Information}

The conversion relation between body-wave magnitude and moment magnitude has been developed on the basis of 500 earthquake events which body-wave magnitude $\left(m_{b}\right)$ and moment magnitude $\left(M_{W}\right)$ were independently reported.

The proposed conversion relations are expressed in Fig. 2. The relationships are given as followed:

SR: $M_{W}=1.038216( \pm 0.013) m_{b}-0.100564( \pm 0.068)$

OR: $M_{W}=1.191018( \pm 0.027) m_{b}-0.909681( \pm 0.148)$

ISR: $M_{W}=1.315352( \pm 0.0001) m_{b^{-}} 1.568054( \pm 0.0001)$

\section{The Conversion of Surface-Wave Magnitude Information}

In order to develop a reliable relationship between magnitude $M_{s}$ and $M_{W}$, regression analysis was applied for two magnitude ranges: (a) events with magnitude $M_{s}<6.1$ and (b) earthquakes with magnitude $6.1 \leq M_{s}$. The conversion relationship of information expressed as surface-wave magnitude has been built on the basis of 423 events $\left(M_{s}<6.1\right)$ for which both measures of magnitude $\left(M_{s}\right.$ and $\left.M_{W}\right)$ were reported independently. The obtained conversion relationship is expressed in Fig. 3.

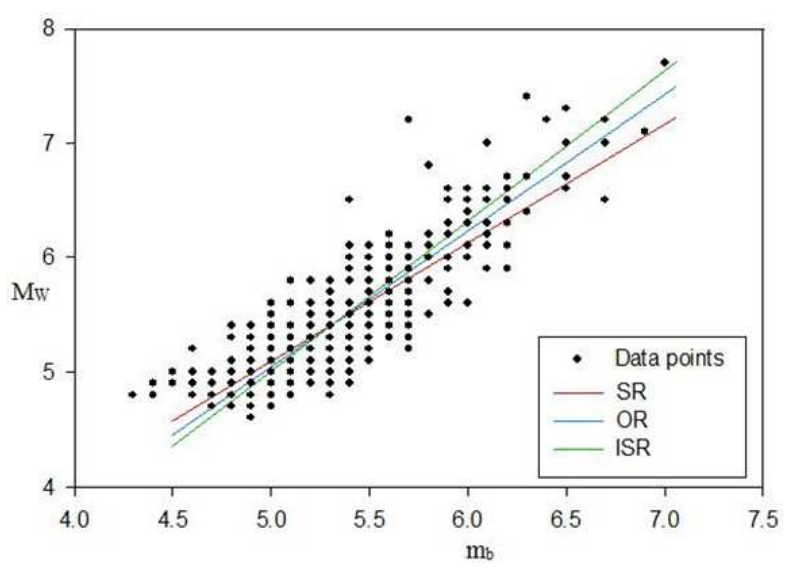

Fig. 2. The regression between $M_{W}$ and $m_{b}$ data

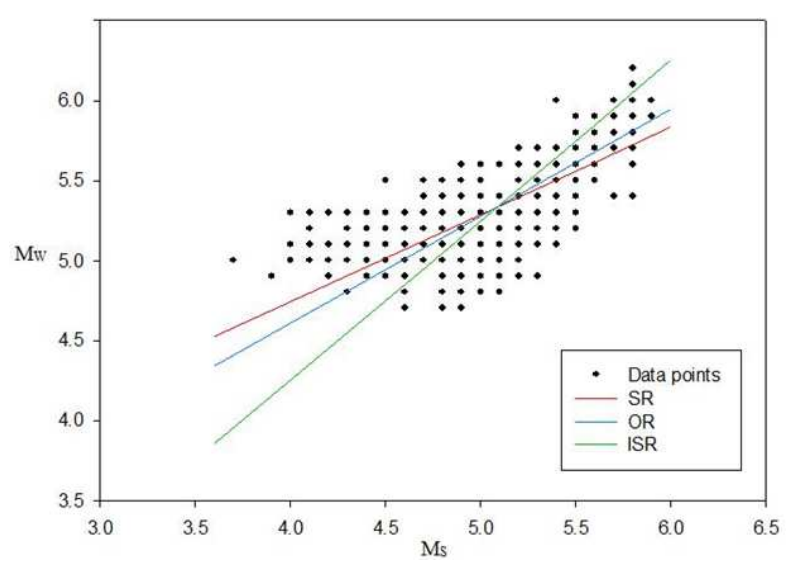

Fig. 3. Regression between $M_{W}$ and $M_{S}$ for $M_{S}<6.1$

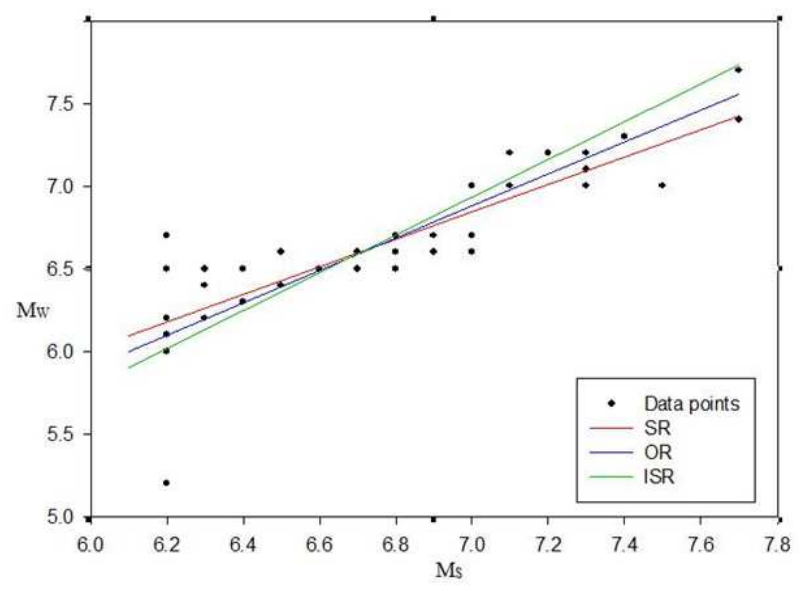

Fig. 4. Regressions between $M_{W}$ and $M_{S}$ for $6.1 \leq M_{s}$

About 42 earthquake events have been considered for conversion of $M_{S}$ magnitudes in the magnitude range of $6.1 \leq M_{s}$ and the relationship is given in Fig. 3 .

The established relationships between $M_{W}$ and $M_{S}$ based on 423 events for $M_{S}<6.1$ are: 
SR: $M_{W}=0.545821( \pm 0.013) M_{S}+2.559413( \pm 0.066)$

OR: $M_{W}=0.667339( \pm 0.029) M_{S}+1.942052( \pm 0.158)$

ISR: $M_{W}=0.998898( \pm 0.0001) M_{S}+0.257606( \pm 0.0001)$

For conversion of higher $M_{S}$ magnitudes in the magnitude range $6.1 \leq M_{S} \leq 7.4$, we considered 42 events and the relationships are given as followed Fig. 4:

SR: $M_{W}=0.834312( \pm 0.043) M_{S}+1.002939( \pm 0.288)$

OR: $M_{W}=0.974457( \pm 0.086) M_{S}+0.059964( \pm 0.568)$

ISR: $M_{W}=1.145546( \pm 0.046) M_{S}-1.091219( \pm 0.307)$

\section{The Conversion of Local Magnitude Information}

About 362 earthquake events of the compiled catalogue with information in local magnitude scale $\left(M_{L}\right)$ and moment magnitude scale $\left(M_{W}\right)$ were available. However, the relationships for the conversion have been built based on them. The proposed conversion relationships between $M_{L}-M_{W}$ are expressed in Fig. 5.

SR and ISR relationships are also plotted along with OR to illustrate the differences of using these methods. The established relationships between $M_{W}$ and $M_{L}$ based on 362 events are:

SR: $M_{W}=0.625359( \pm 0.020) M_{L}+2.229484( \pm 0.088)$

OR: $M_{W}=0.913323( \pm 0.054) M_{L}+0.949395( \pm 0.271)$

ISR: $M_{W}=1.416868( \pm 0.0001) M_{L}-1.289013( \pm 0.0001)$

Castellaro and Bormann (2007) suggested calculating OR, SR and ISR. Their study presented that if slope of OR lies in the angular midst between slope of SR and slope of ISR and slope of $\mathrm{OR} \approx 1$, then slope of OR is the best regression because in this case, slope of $\mathrm{OR}$ is equal to slope of GOR so in this study for all magnitudes slope of OR were considered as the best regression. In order to create a uniform catalogue in terms of magnitude, if is available must use, otherwise, one of the calculated equations must be used to convert to moment magnitude (Karimiparidari et al., 2013).

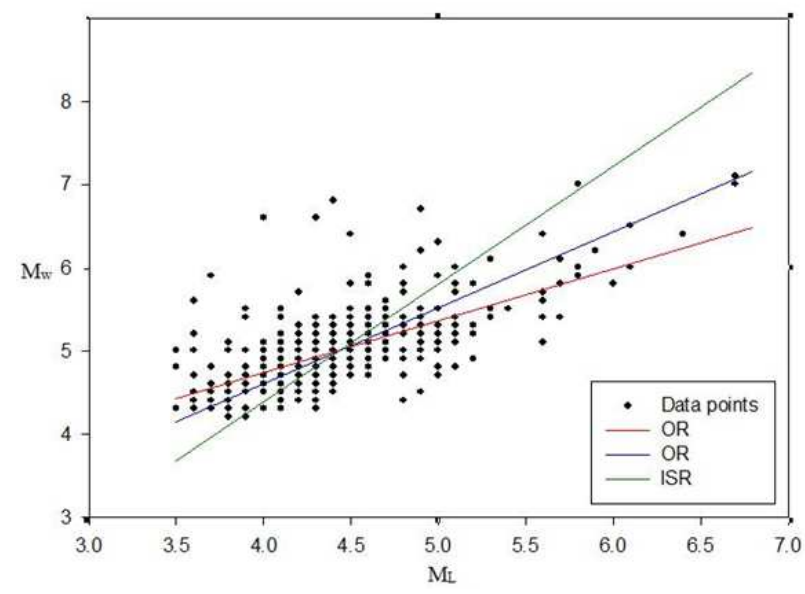

Fig. 5. Regression between $M_{L}$ and $M_{W}$ data

\section{Discussion and Conclusion}

The new seismic event catalogue contains data from the third millennium $\mathrm{BC}$ to 2014. Orthogonal Regression (OR) method was applied to develop several relationships between different types of magnitudes in order to standardize catalogue in terms of magnitude.

Scordilis (2006) investigated empirical global relations converting, $m_{b}$ and $M_{S}$ to moment magnitude and Karimiparidari et al. (2013) developed relations to convert $m_{b}, M_{S}, M_{N}$ and $M_{L}$ into moment magnitude in Iran.

Comparing the results of the present study with a similar investigation done by (Scordilis, 2006; Karimiparidari et al., 2013) for $m_{b}$ and $M_{S}$ to $M_{W}$ and only with (Karimiparidari et al., 2013) for $M_{L}$ to $M_{W}$ have been shown in Fig. 6 to 8 .

Generally, result of linear regression models in this study is properly similar with the other studies for $M_{W}$ via $M_{S}$ conversion but for $M_{W}$ via $m_{b}$ the results are significantly different and it can be clearly seen that new relations are more similar to Karimiparidari et al. (2013). The new relationship yields slightly lower $M_{W}$. The differences between the results of this study beside other studies might be because of using different methods or different magnitude ranges.

Figure 8 shows that the $M_{L}-M_{W}$ curves are significantly different and the new relationship yields slightly higher.

As the procedures and priorities are established, updating this catalog should be a straightforward task. There was a lack of sufficient evidence about some historical events, so they were omitted. A future study on Iranian historical earthquakes to consider probable fake events is also recommended.

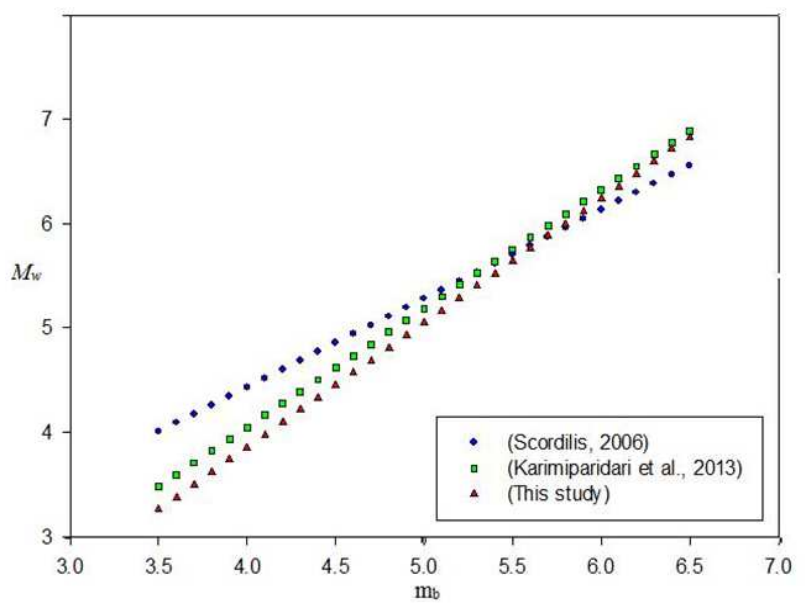

Fig. 6. Result comparison of this study with $M_{W}$ versus $m_{b}$ obtained by (Scordilis, 2006; Karimiparidari et al., 2013) 


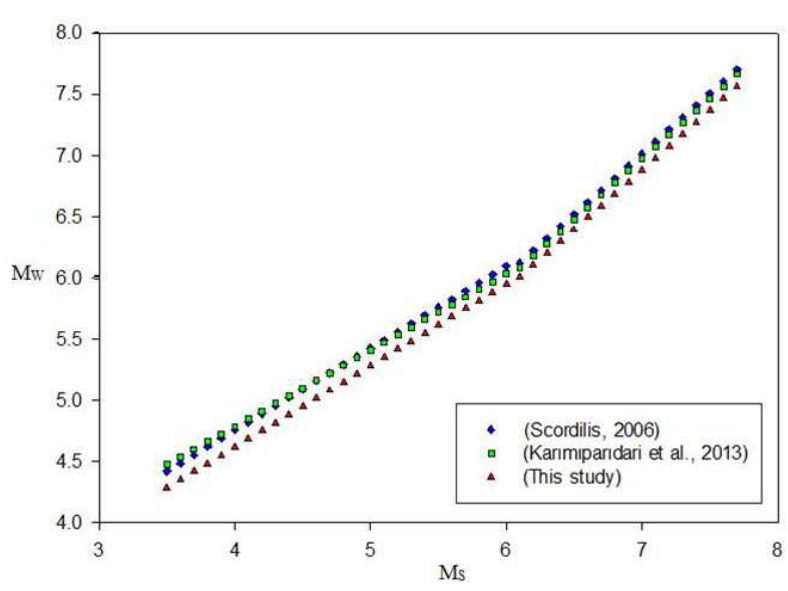

Fig. 7. Comparison result of this study with $M_{W}$ versus $M_{S}$ obtained by (Scordilis, 2006; Karimiparidari et al., 2013) for $3<\mathrm{M}_{\mathrm{S}}<6.1$

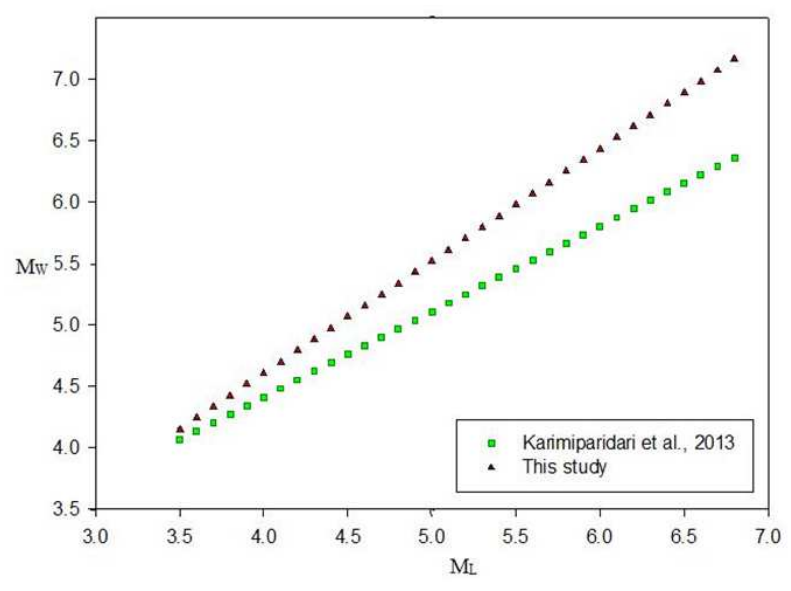

Fig. 8. Comparison result of this study with $M_{W}$ versus $M_{L}$ and Karimiparidari et al. (2013)

\section{Acknowledgement}

Researchers are grateful to University Science Malaysia for support this research.

\section{Author's Contributions}

Noushin Naraghiaraghi: Designed the study, collected data, made the interpretation and wrote the manuscript.

Mohd Nawawi: Collected data and made the interpretation and edited the manuscript.

Syed Mustafizur Rahman: Wrote the manuscript.

Ali Beitollahi: Collected data.

Rosli Saad: Wrote the manuscript.

Samieh Joneidi: Collected data.

\section{Ethics}

This article is original. All authors have read and approved the manuscript and no ethical issues involved.

\section{References}

Ambraseys, N.N. and C.P. Melville, 1982. A History of Persian Earthquakes. 1st Edn., Cambridge University Press, Cambridge, ISBN-10: 52124112X, pp: 236.

Ambraseys, N.N., 1990. Uniform magnitude reevaluation of European earthquakes associated with strong-motion records. Earthquake Eng. Structural Dynamics, 19: 1-20. DOI: 10.1002/eqe.4290190103

Berberian, M., 1994. Natural Hazards and the First Earthquake Catalogue of Iran. 1st Edn., International Institute of Earthquake Engineers and Seismology, pp: 603.

Bird, P. and Y.Y. Kagan, 2004. Plate-tectonic analysis of shallow seismicity: Apparent boundary width, beta, corner magnitude, coupled lithosphere thickness and coupling in seven tectonic settings. Bull. Seismol. Soc. Am., 94: 2380-2399.

DOI: $10.1785 / 0120030107$

Carroll, R. and D. Ruppert, 1996. The use and misuse of orthogonal regression in linear errors-in-variables models. Am. Statist., 50: 1-6. DOI: $10.1080 / 00031305.1996 .10473533$

Castellaro, S. and P. Bormann, 2007. Performance of different regression procedures on the magnitude conversion problem. Bull. Seismol. Society Am., 97: 1167-1175. DOI: 10.1785/0120060102

Cavallini, F. and A. Rebez, 1996. Representing earthquake intensity-magnitude relationship with a nonlinear function. Bull. Seismol. Society Am., 86: 73-78.

Das, R., H.R. Wason and M.L. Sharma, 2012. Homogenization of earthquake catalog for northeast India and adjoining region. Pure Applied Geophys., 169: 725-731. DOI: 10.1007/s00024-011-0339-6

Gusev, A.A., 1991. Intermagnitude relationships and asperity statistics. Pure Applied Geophys., 136: 515-527. DOI: 10.1007/BF00878585

Gutdeutsch, R., D. Kaiser and G. Jentzsch, 2002. Estimation of earthquake magnitudes from epicentral intensities and other focal parameters in Central and Southern Europe. Geophys. J. Int., 151: 824-834. DOI: 10.1046/j.1365-246X.2002.01804.x

Jarahi, H., N. Naraghiaraghi and M. Nadalian, 2016. Short period spectral acceleration zonation of tehran a comparison between slip and activity rates data's. Am. J. Geosci.

DOI: $10.3844 /$ ofsp. 10450

Joshi, G.C. and M.L. Sharma, 2008. Uncertainties in the estimation of $M_{\max }$. J. Earth Syst. Sci., 117: 671-682. DOI: $10.1007 / \mathrm{s} 12040-008-0063-5$

Kagan, Y.Y., 2002a. Seismic moment distribution revisited: II. Moment conservation principle. Geophys. J. Int., 149: 731-754.

DOI: 10.1046/j.1365-246X.2002.01671.x 
Kagan, Y.Y., 2002b. Modern california earthquake catalogs and their comparison. Seism. Res. Lett., 73: 921-929. DOI: 10.1785/gssrl.73.6.921

Kagan, Y.Y., 2003. Accuracy of modern global earthquake catalogs. Phys. Earth Planetary Interiors, 135: 173-209. DOI: 10.1016/S0031-9201(02)00214-5

Kanamori, H., 1983. Magnitude scale and quantification of earthquakes. Tectonophysics, 93: 185-199. DOI: 10.1016/0040-1951(83)90273-1

Karimiparidari, S., M. Zare, H. Memarian and A. Kijko, 2013. Iranian earthquakes, a uniform catalog with moment magnitudes. J. Seismol., 17: 897-911. DOI: $10.1007 / \mathrm{s} 10950-013-9360-9$

Kasahara, K., 1981. Earthquake mechanics. Cambridge University Press Cambridge.

Kaverina, A.N., A.V. Lander and A.G. Prozorov, 1996. Global creepex distribution and its relation to earthquake-source geometry and tectonic origin. Geophys. J. Int., 125: 249-265. DOI: 10.1111/j.1365-246X.1996.tb06549.x

Kendall, M.G. and A. Stuart, 1946. The advanced theory of statistics. Charles Griffin and Co, London.

Madansky, A., 1959. The fitting of straight lines when both variables are subject to error. J. Am. Statist. Associat., 54: 173-205.

Panza, G.F., A.G. Prozorov and G. Pazzi, 1993. Extension of global creepex definition $\left(M_{s}-m_{b}\right)$ to local studies $\left(M_{d}-M_{L}\right)$ : The case of the Italian region. Terra Nova, 5: 150-156.

DOI: 10.1111/j.1365-3121.1993.tb00240.x
Richter, C.F., 1935. An instrumental earthquake magnitude scale. Bull. Seismol. Soc. Am., 25: 1-32.

Ristau, J., 2009. Comparison of magnitude estimates for New Zealand earthquakes: Moment magnitude, local magnitude and teleseismic body-wave magnitude. Bull. Seismol. Society Am., 99: 1841-1852. DOI: $10.1785 / 0120080237$

Scordilis, E.M., 2006. Empirical global relations converting $M_{S}$ and $m_{b}$ to moment magnitude. J. Seismol., 10: 225-236. DOI: $10.1007 / \mathrm{s} 10950-006-9012-4$

Singh, S., M. Rodriguez and L. Esteva, 1983. Statistics of small earthquakes and frequency of occurrence of large earthquakes along the Mexican subduction zone. Bull. Seismol. Society Am., 73: 1779-1796.

Stromeyer, D., G. Grünthal and R. Wahlström, 2004. Chisquare regression for seismic strength parameter relations and their uncertainties, with applications to an $M_{w}$ based earthquake catalogue for central, northern and northwestern Europe. J. Seismol., 8: 143-153. DOI: 10.1023/B:JOSE.0000009503.80673.51

Thingbaijam, K.K.S., S.K. Nath, A. Yadav, A. Raj and M.Y. Walling et al., 2008. Recent seismicity in Northeast India and its adjoining region. J. Seismol., 12: 107-123. DOI: 10.1007/s10950-007-9074-y 